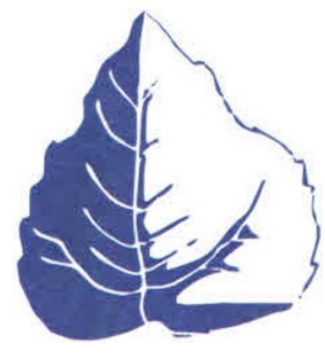

УДК 332.1

\section{ЭКОЛОГИЯ (ПО ОТРАСЛЯМ) ECOLOGY (ITS BRUNCHES)} особо охраняемых территорий Ростовского региона

\author{
А. Д. Мурзин, Р. В. Ревунов \\ Южный федеральный университет, г. Ростов-на-Дону, Российская Федерация
}

\title{
Environmental and economic conditions and regulatory mechanisms for the formation of Rostov region specially protected areas
}

\author{
A. D. Murzin, R. V. Revunov \\ Southern Federal University, Rostov-on-Don, Russian Federation
}

Формирование и развитие особо охраняемых территорий приобретает исключительно важное значение не только с экологической точки зрения, но и с экономической и особенно - с социальной. Поэтому решение сложных задач по обоснованию территориального обустройства природохозяйственной деятельности, включая и рекреационную, приобретает все большее значение, и общество вынуждено планировать комплекс мероприятий по охране окружающей среды.

Рассматриваются современные особенности природохозяйственной практики Ростовской области на микро- и мезоэкономическом уровнях, анализируются полномочия органов местного самоуправления в сфере природопользования и создания особо охраняемых природных территорий, предлагаются направления повышения социо-эколого-экономической эффективности регионального природопользования.

Ключевые слова: Ростовская область, природопользование, регион, особо охраняемые природные территории, социо-экологоэкономический ущерб.

Образец для цитирования: Мурзин, А. Д. Эколого-экономические условия и нормативно-правовые механизмы формирования особо охраняемых территорий Ростовского региона / А. Д. Мурзин, Р. В. Ревунов // Эконо-
Formation and development of protected areas has an extreme importance, not only from an environmental point of view but also from an economic and especially social one. Therefore, the solution of complex problems in the justification of the territorial arrangement of natural activities, including recreation, is becoming increasingly important, and the society is forced to plan a set of measures to protect the environment. We consider the current features of Rostov region, its natural practices at the micro and mesa levels, powers of local selfgovernment bodies in the sphere of nature and the creation of protected areas are analyzed, ways of increasing socio-environmental and economic efficiency of regional nature is taken into account.

Keywords: Rostov region, nature, region, protected areas, social, ecological and economic damage.

For citation: A. D. Murzin, R. V. Revunov.

Environmental and economic conditions and regulatory mechanisms for the formation of Rostov region specially protected areas. Economy and ecology of territorial formations, 2019, vol. 3, no. 1, pp. 
мика и экология территориальных образований.

- 2019. - T. 3, № 1. - C. 46-55.

https://doi.org/10.23947/2413-1474-2019-3-1-46-

\section{$\underline{55}$}

Введение. Современный Ростов-на-Дону - это столица одноименной области, фактически сложившийся крупный конгломерат, по величине уступающий только Московскому и Питерскому. В его состав, кроме административного центра, входят пять городов-спутников: Таганрог, Шахты, Новочеркасск, Волгодонск и Новошахтинск. В Ростове-на-Дону проживает около 1,1 млн человек, примерно столько же жителей насчитывается во всех крупных городах области вместе взятых. Каждый из перечисленных городов является мощным индустриальным образованием, вносящим свой вклад в общий экологический фон Ростовской области.

В административном центре Ростовской области сосредоточены крупные предприятия различного профиля: ОАО «Ростсельмаш», ОАО «Роствертол», ЗАО «Эмпилс», ОАО «Балтика-Дон», ОАО «Донской табак», ЗАО «Агат», Ростовская ТЭЦ и др. В последние десятилетия усредненные выбросы вредных веществ от стационарных источников составляют около 150 тыс. т. Средние объемы выбросов от стационарных источников по крупным городам области: Ростов-на-Дону 10 тыс. т, Новочеркасск - 62 тыс. т., Таганрог - 7 тыс. т, Шахты - 4 тыс. т, Волгодонск - 3 тыс. т, Новошахтинск, Батайск, Азов - по 1 тыс. т. Поэтому решение проблем по защите окружающей природной среды приобретает важное значение в современных условиях. Цель данной работы в связи с этим - анализ проблем загрязнения окружающей среды в Ростовской области и в Ростове-на-Дону, а также путей минимизации негативных последствий природопользования промышленнохозяйственных агломераций [1-7].

Исследование проблем окружающей природной среды и ее нормативно-правовое обеспечение. Известно, что выбросы загрязняющих веществ проникают и аккумулируются во всех природных средах региона. Среднегодовой объем выбросов загрязняющих веществ в атмосферу города Ростова-на-Дону составляет 146 тыс. т, из них более 90 \% приходится на автомобильный транспорт, количество единиц которого с каждым годом увеличивается. Лидирующие по загрязнению муниципальные образования Ростовской области ежегодно поставляют в атмосферный бассейн до двух тонн формальдегида, до 300 тонн летучих газообразных соединений, до 15 тонн метана, до 200 тонн твёрдых пылеватых частиц и т. д.

Достаточно высок совокупный уровень техногенного воздействия на водные объекты Ростовской области. Высокий уровень износа объектов водохозяйственной инфраструктуры, устарелость применяемых технологий очистки не позволяют обеспечить надлежащую переработку сточных вод. В результате в акваторию водных объектов Ростовской области попадают нефтепродукты, поверхностно-активные вещества, фенолы, минеральные и органические взвеси, хлориды, сульфаты, нитраты, аммиак, тяжёлые металлы и другие загрязнители. Особенно сложная экологическая ситуация наблюдается в акваториях водных объектов, расположенных в ареалах крупнейших промышленнохозяйственных агломераций региона. В частности, река Темерник, воспринимающая антропогенное воздействие Ростова-на-Дону, принимает ежегодно около 100 млн м³ неочищенных или недостаточно очищенных сточных вод, что в 15 раз больше природного стока с водосбора.

Ежегодно в поверхностные водные объекты поступает 1723 млн м³ , почти $1 / 5$ из них - загрязнённые воды. Суммарная мощность водоочистки перед сбросом в акватории - 672 млн м³. Подобный дисбаланс приводит к тому, что в важнейшие источники водоснабжения Ростовской области, каковыми являются поверхностные воды Дона, реки бассейна Дона, Цимлянское водохранилище, поступают загрязняющие вещества, создающие риск здоровью граждан и дестабилизирующие экосистемы.

Основные предприятия-загрязнители атмосферного воздуха Ростовской области: ПАО «Вторая генерирующая компания оптового рынка электроэнергии», в собственности которой 
находится Новочеркасская тепловая электростанция - вклад в загрязнение атмосферного бассейна составляет до 58 \%, МУП «Теплокоммунэнерго», Волгодонская ТЭЦ-2, ОАО «Ростсельмаш», Ростовская ТЭЦ-2, АО «Трансмашхолдинг» - контролирующий собственник ООО «Промышленная компания «Новочеркасский электровозостроительный завод», «Донской кирпич», $\mathrm{OOO}$ «Аристотель», ОАО «Новочеркасский электродный завод» - объёмы выбросов указанных хозяйствующих субъектов колеблются в диапазоне от 1,6 до 0,4 \% от совокупной эмиссии вредных веществ в атмосферный бассейн Ростовской области.

Говоря об эколого-экономическом состоянии Ростовской области, нельзя не отметить высокий уровень ежегодного образования отходов. Лидирующей отраслью экономики по масштабам формирования отходов является добыча и переработка угля, чей вклад в совокупный объём ежегодно формирующихся на территории Ростовской области отходов превышает 50 \% (в абсолютных значениях 4 млн т). Экологически несбалансированная природохозяйственная практика угледобывающей отрасли ухудшает качество земельных угодий, т. к. площадь отвалов шахт занимает до 1 тыс. га.

Помимо указанной негативной тенденции значительного отходообразования промышленности, необходимо отметить возрастающий объём твёрдых коммунальных отходов. Одной из наиболее острых экологических проблем Ростовской области является нерешённый вопрос эффективной утилизации бытовых отходов. Для крупных городов региона характерно большое количество несанкционированных свалок, часто расположенных в водоохранных зонах, вблизи важных социальных объектов. С 1999 года в Ростове-на-Дону действует модернизированный полигон твёрдых бытовых отходов, аналога которому нет на Северном Кавказе. Влияние его на окружающую среду минимально. С 2002 года работает первый в Южном федеральном округе Ростовский мусороперерабатывающий комплекс. Однако мощности указанных объектов недостаточно для экологически безопасной утилизации отходов Ростовской промышленно-хозяйственной агломерации. Необходимо формирование институциональных, организационно-экономических, административно-правовых предпосылок для развития сети экологически безопасных мусороперерабатывающих комплексов на всей территории Ростовской области.

Почвенно-земельные ресурсы региона, как и другие компоненты природной среды, также подвергаются интенсивному антропогенному воздействию, провоцирующему развитие таких негативных процессов, как водная и ветровая эрозия, потери гумуса, переувлажнение, засоление, осолонцевание, загрязнение почв и грунтов ядовитыми веществами. Эрозии подвержено свыше 35 \% сельскохозяйственных угодий. В восточных районах Ростовской области наблюдаются процессы опустынивания. Вследствие недостатка финансирования строительство полезащитных лесополос и противоэрозионных овражно-балочных насаждений осуществляется на 10-20 \% от необходимого масштаба.

Как показывают результаты наблюдений в Ростове-на-Дону, суммарный индекс загрязнения для разных почв выше единицы (в лесопарковой зоне в среднем колеблется около 1,6). Превышение содержания ПДК по подвижным формам $\mathrm{Mn}, \mathrm{Zn}, \mathrm{Cu}, \mathrm{Pb}, \mathrm{Cd}$ не выявлено. Максимальные показатели наблюдаются для цинка, свинца, меди. В промышленной зоне фиксируется наибольший уровень загрязнения, в частности, превышение предельно допустимых концентраций по общему содержанию металлов в 2,5-5 раз выше нормы.

На окружающую среду оказывают влияние 12 промышленных предприятий, 6 железнодорожных магистралей, 10 автомобильных трасс общегосударственного значения и более 10 нефте- и газопроводов. Дон, на берегу которого расположился Ростов, в нижнем своем течении также подвергается значительным техногенным нагрузкам: в него сбрасывают отходы, по нему курсируют суда, его воды используют для водоснабжения населения и орошения сельхозугодий.

Более половины всех загрязнений дает Новочеркасская тепловая электростанция — видимые из космоса остатки ее дымного шлейфа окончательно рассеиваются в районе Варны. Муниципальное унитарное предприятие «Теплокоммунэнерго», ТЭЦ-2, заводы «Ростсельмаш», «Роствертол» и «Эмпилс» ежегодно выбрасывают в окружающую среду 2,5 тысячи тонн отходов. И все же, по мнению экспертов, основной антропогенный фактор в Ростове - автомобиль. Поэтому, несмотря на относи- 
тельно «спокойную» (по сравнению с другими городами) экологическую обстановку, уровень загрязнения городских районов различается. В спальных муниципальных зонах уровень загрязненности удовлетворителен, где-то содержание токсических веществ в атмосфере превышает норму в 50 раз.

По административной градации город разбит на восемь территориально-административных районов. Ленинский район охватывает центральные улицы Ростова. Здесь сосредоточено большинство культурных памятников, центральных учреждений, вузов, торговых центров. Здесь же сохранились изношенные сети городского водоснабжения и канализации, изрядно обветшалые жилые дома, узкие улицы. Этот район - лидер по количеству пыли, выпадающей на единицу площади, ширине спектра осаждающихся токсических соединений, загазованности. С его улиц ежегодно с ливневыми стоками выносится в Дон сотни тонн извести, свинца, нефтепродуктов, сернистых и хлористых солей. По результатам проведенного врачами обследования, жители этого района более других страдают от заболеваний и функциональных расстройств.

Ворошиловский район охватывает северную часть города. Один из его микрорайонов так и называется - Северный жилой массив, в нем сосредоточена основная доля жилого фонда. Здесь живут $20 \%$ ростовчан. Эта часть города граничит с наиболее чистыми ростовскими территориями. Однако расположенные в границах района ТЭЦ-2 и полигон ТБО значительно ухудшают комфортность проживания. В воздухе наблюдается повышенное содержание сульфидов, нитратов. И все же такие факторы, как новый неизношенный жилой фонд, комплексная застройка, близость к центру города, наличие зеленых насаждений в частном секторе, обеспечивают популярность жилья в этом районе.

На территории Ворошиловского района проживает почти пятая часть жителей Ростова-наДону, располагаются крупные промышленные предприятия, в том числе три военно-промышленных комплекса.

Кировский район - исторический центр Ростова, объединен главной улицей с Ленинским Большой Садовой. Одна из самых напряженных городских артерий является в то же время наименее зеленой. Кировский район - сосредоточие административных зданий, учебных корпусов вузов, многоэтажных офисов. Современные небоскребы здесь соседствуют с архитектурными памятниками. Жилая застройка XIX века за ухоженными фасадами скрывает видавшие лучшие времена коммуникации. В этом административном образовании расположены предприятия РЗЖБК, «Тавр», «Спецстрой», мясокомбинат, «Рубин».

Насыщенность улиц автомобильным транспортом, плотность застройки, наличие промышленных предприятий обеспечивают высокий уровень загрязненности воздушного пространства улиц и площадей. Среди веществ, которые выпадают в осадок на территории района - сульфиды, нитраты аммиака, цинк, хром. Более 40 \% легких органических соединений, которые содержатся в городской атмосфере, выбрасывают предприятия района.

Октябрьский район расположен на северо-западе мегаполиса, считается одним из наиболее благополучных в экологическом отношении. Эта городская часть - результат послевоенного и современного развития города. В ней обосновались ученые, проектировщики, врачи: шесть научноисследовательских институтов и два учебных заведения построены здесь. Тем не менее, по данным экологов, в этой городской зоне количество пылевых осадков с повышенным содержанием свинца значительно превышает норму. Компания «Теплокоммунэнерго» устойчивыми темпами «поставляет» в атмосферу $72 \%$ от общегородского количества оксидов углерода.

Пролетарский район замыкает город с восточной стороны. Также относится к благополучным (в плане соответствия экологическим нормам) территориям. В этой части города расположились инженерные сооружения, обеспечивающие город водой, электроэнергией, газом. На улицах района осаждается не более 17 \% от совокупности твердых веществ.

Первомайский - это район, в котором образуется более трети городских вредных посторонних атмосферных примесей. В районе расположился флагман тракторостроения «Ростсельмаш». В высотных домах, составляющих основу городской застройки, проживает 17 \% населения Ростова. 
Железнодорожный район: название говорит само за себя. Застройка в этих местах не отличается высокой плотностью - не более $10 \%$ ростовчан проживает на едва ли не самой обширной городской территории. С точки зрения экологов, это чистый район. Сосредоточенные здесь предприятия (депо, железнодорожные станции, сортировки, ремонтные мастерские) хотя и являются источником загрязнений, но небольшим. Частные дома в окружении плодовых деревьев обеспечивают сбалансированность экосистемы. В составе района несколько поселков. Несмотря на высокое качество природных условий для проживания количество населения неуклонно снижается: молодежь предпочитает селиться ближе к центральным, густонаселенным районам.

Советский район - западные ворота Ростова. Его можно назвать продуктом инженерной мысли новейшего времени. Строительство Советского велось с учетом максимальной обеспеченности объектами быта, торговли, инфраструктуры. Транспортное сообщение этой части с другими городскими территориями осуществляется по многорядной автомагистрали. Район насыщен промышленными объектами. Здесь расположено химическое предприятие «Эмпилс», ряд других производств. Но все же, несмотря на большое количество промышленных выбросов, условия для проживания в Советском можно назвать удовлетворительными.

Приоритетным источником питьевого водоснабжения для граждан, проживающих в Ростовской области, является река Дон, поставляющая более 93 \% питьевых водных ресурсов. По мере течения от расположенного в Тульской области истока к устью в районе Азовского моря воды Дона подвергаются значительному антропогенному воздействию, что приводит к их существенной модификации. Указанный водный объект является безальтернативным источником водоснабжения для городов и населённых пунктов таких субъектов Российской Федерации, как Липецкая, Воронежская, Рязанская, Волгоградская, Ростовская области. Комплекс гидротехнических сооружений, расположенных в водосборном бассейне Дона, способствует ухудшению качества воды вследствие нерационального водопользования. В частности, расположенное недалеко от Ростовской агломерации Цимлянское водохранилище аккумулирует значительные объёмы сточных вод, поступающих от хозяйствующих субъектов-водопользователей. Подобная тенденция, наблюдаемая на протяжении нескольких лет, провоцирует ускоренное развитие опасных сине-зелёных водорослей.

В силу действия исторических и географических факторов в ареале бассейна Дона расположено большое количество объектов промышленно-хозяйственной инфраструктуры, водохозяйственная практика которых отличается ресурсорасточительными и экологически деструктивными признаками. Интенсивная техногенно-антропогенная нагрузка на акваторию способствует превышению в воде предельно допустимых концентраций нефтепродуктов в 1,3 раза, сульфатов, солей меди - более чем в 3 раза. Также выявлено наличие фенолов, нитратов и других загрязнителей. Воды, используемые для обеспечения жизнедеятельности людей, соответствуют уровню «умеренно загрязненных».

Состояние зеленых зон. Город расположен в степной зоне, поэтому городские скверы, парки, аллеи - результат больших усилий человека. Интенсивность развития города, неравномерная плотность застройки отдельных его территорий в разные времена привела к недостаточному озеленению многих улиц. Общая обеспеченность мегаполиса зелеными насаждениями на 70 \% не дотягивает до принятых норм. На протяжении ряда последних лет городские жители высадили десятки тысяч деревьев с целью обеспечить Ростов достаточным количеством зеленых зон.

В атмосферу предприятиями и автотранспортом выбрасывается ежегодно более 490 тыс. тонн вредных веществ. При этом доля промышленных предприятий в антропогенном химическом кругообороте непрерывно снижается по разным причинам. Среди них установка очистных сооружений, сокращение объемов производства, перевод мощностей из густонаселенных районов на новые промышленные площадки. Ростовская администрация оказывает заметное влияние на вывод промышленных объектов за пределы города. Так, по ее инициативе в последние годы было передислоцировано более 10 предприятий, среди них бумажно-картонажные, химические, печатные. 
Более существенное влияние на качество воздушной среды оказывает автомобильный транспорт. Его доля в загрязнении атмосферы вредными примесями превышает 70 \%. Львиная доля автомобилей, интенсивно передвигающихся по дорогам города, принадлежит индивидуальным владельцам. По этой причине местные власти могут лишь опосредствованно воздействовать на ситуацию. Одним из путей такого влияния на количество выбросов является строительство новых магистралей. Ростовские власти на протяжении последних лет ввели несколько участков новых автодорог. Несмотря не неплохое качество объездных магистралей продолжается строительство современных путепроводов, предназначенных для разгрузки от транспорта центральных улиц.

Законодательство Российской Федерации устанавливает правовые основы создания и функционирования особо охраняемых природных территорий. Согласно статье 42 Конституции РФ, каждый имеет право на благоприятную окружающую среду, достоверную информацию о ее состоянии и на возмещение ущерба, причиненного его здоровью или имуществу экологическим правонарушением [8]. Во исполнение указанной правовой нормы природопользование, охрана окружающей среды и обеспечение экологической безопасности, особо охраняемые природные территории и др. отнесены к предмету совместного ведения Российской Федерации и субъектов Российской Федерации [8]. Также к предмету совместного ведения отнесено земельное, водное, лесное законодательство, законодательство о недрах, об охране окружающей среды.

Реализация указанных конституционных норм осуществлена в федеральном законодательстве, разграничивающем и конкретизирующем юрисдикции, полномочия, обязанности, ответственность Российской Федерации, субъектов РФ, органов местного самоуправления по вышеуказанным вопросам. Земельным кодексом РФ (ст. 94) установлен порядок и состав земель особо охраняемых территорий [9]. Согласно указанному законодательному акту, к землям особо охраняемых территорий относятся земли, которые имеют особое природоохранное, научное, историко-культурное, эстетическое, рекреационное, оздоровительное и иное ценное значение, которые изъяты в соответствии с постановлениями федеральных органов государственной власти, органов государственной власти субъектов Российской Федерации или решениями органов местного самоуправления полностью или частично из хозяйственного использования и оборота и для которых установлен особый правовой режим [9].

Органы государственной власти субъектов Российской Федерации и органы местного самоуправления имеют полномочия по отнесению земель, расположенных в пределах их административных границ, к категории особо охраняемых территорий на основании законов субъектов Российской Федерации и нормативных правовых актов органов местного самоуправления

В связи с реализацией установленных Конституцией полномочий органами государственной власти Ростовской области сформирована база законодательных и нормативно-правовых актов, формирующих процедуру создания и функционирования ООПТ в регионе: это областной закон от 28 декабря 2005 г. № 434-3С «Об особо охраняемых природных территориях Ростовской области», постановление правительства РО от 15 мая 2014 г. № 350 «Об утверждении Порядка организации и функционирования особо охраняемых природных территорий Ростовской области».

Анализ вышеуказанных документов позволяет говорить о том, что создание ООПТ является долгосрочной, трудоёмкой процедурой, требующей капиталовложений, в том числе на этапе подготовки обосновательной документации. Подобный подход, с одной стороны, защищает от реализации недостаточно проработанных природоохранных проектов, с другой - затрудняет оперативную реакцию органов государственной власти субъекта РФ на изменение социо-эколого-экономической ситуации.

С учётом сказанного авторам представляется, что необходимо разработать и ввести на законодательном уровне различные категории региональных ООПТ, дифференцированные по степени природоохранной значимости. В свою очередь, для каждой из данных категорий ООПТ может быть определён свой порядок создания и ликвидации. Практическое воплощение подобного предложения 
позволит учесть природохозяйственную специфику субъекта РФ и обеспечить максимально эффективное функционирование ООПТ.

Органы местного самоуправления в рамках реализации установленных законом «Об общих принципах организации местного самоуправления в Российской Федерации» полномочий могут создавать в пределах своих административных границ особо охраняемые природные территории [10]. При этом пунктом 3 статьи 14 закона вопросы использования, охраны, защиты, воспроизводства городских лесов, лесов особо охраняемых природных территорий, расположенных в границах населенных пунктов поселения, исключены из компетенции органов местного самоуправления сельского поселения и отнесены к компетенции муниципального района.

С учётом вышеизложенного представляет интерес опыт города Новочеркасска, на территории которого в 2017 г. была создана особо охраняемая природная территория местного значения «Роща «Красная весна» [11]. Придание единственной сохранившейся городской роще статуса ООПТ позволило не только обеспечить правовую защиту от вырубки и застройки, но и расширило возможности Новочеркасска по участию в федеральных программах формирования комфортной городской среды, развития экологического туризма.

Права и обязанности органов местного самоуправления в области регулирования природопользования отражены в табл. 1.

Таблица 1

Полномочия органов местного самоуправления в сфере природопользования

и создания особо охраняемых природных территорий [10]

\begin{tabular}{|c|c|}
\hline $\begin{array}{l}\text { Административная } \\
\text { единица местного } \\
\text { самоуправления }\end{array}$ & Содержание регулирующих функций \\
\hline $\begin{array}{l}\text { Городское } \\
\text { поселение }\end{array}$ & $\begin{array}{l}\text { - участие в организации сбора (включая раздельный) и вывоза мусора; } \\
\text { - утверждение нормативных актов по благоустройству территории поселения и } \\
\text { надзор за их соблюдением, благоустройство территории на основе установленных норм, } \\
\text { организация использования, охраны, защиты, воспроизводства городских лесов, лесов } \\
\text { ООПТ на территории городского поселения; } \\
\text { - организация муниципального контроля в сфере использования и ООПТ местного } \\
\text { значения }\end{array}$ \\
\hline $\begin{array}{c}\text { Муниципальный } \\
\text { район }\end{array}$ & $\begin{array}{l}\text { - организация мероприятий межпоселенческого характера по охране окружающей } \\
\text { среды; } \\
\quad \text { - участие в организации работ по сбору (в том числе раздельному) и утилизации } \\
\text { надлежащими способами твёрдых бытовых отходов на территориях соответствующих } \\
\text { муниципальных районов; } \\
\quad \text { - организация муниципального контроля в сфере использования и ООПт местного } \\
\text { значения }\end{array}$ \\
\hline Городской округ & $\begin{array}{l}\text { - организация природоохранных мероприятий на территории городского округа; } \\
\text { - участие в организации работ по сбору и утилизации надлежащими способами } \\
\text { твёрдых бытовых отходов на территории городского округа; } \\
\text { - утверждение нормативных актов, касающихся благоустройства территории посе- } \\
\text { ления, надзор за их соблюдением, благоустройство территории на основе установленных } \\
\text { норм, организация использования, охраны, защиты, воспроизводства городских лесов, } \\
\text { лесов ООПТ на территории городского округа; } \\
\text { - осуществление муниципального контроля в области использования и охраны } \\
\text { ООПТ местного значения. }\end{array}$ \\
\hline
\end{tabular}

Выводы и предложения. Подводя итог сказанному, авторы формулируют следующие основные выводы:

1. Законодательством Российской Федерации установлены основы развития системы особо охраняемых природных территорий. Органы государственной власти субъектов РФ, а также органы местного самоуправления располагают необходимыми административно-правовыми ресурсами для регулирования природопользования на микро- и мезоэкономическом уровнях. 
2. Одним из факторов, определяющих природохозяйственную специфику Ростовской области, является неравномерность территориальной локализации объектов транспортно-логистической и промышленно-хозяйственной инфраструктуры, сконцентрированных в основном на территориях крупнейших промышленно-хозяйственных агломераций: Белокалитвинской, Волгодонской, Красносулинской, Новошахтинской, Новочеркасской, Ростовской, Таганрогской, Шахтинской. Указанная диспропорция приводит к значительной дифференциации техногенного воздействия на природную среду. В результате административно-территориальные образования Ростовской области по уровню экологического благополучия ранжируются от сравнительно благополучных до экстремально загрязнённых.

3. Генерируемое природопользователями Ростовской области неблагоприятное воздействие на природную среду провоцирует следующие деструктивные социо-эколого-экономические последствия: рост экологически обусловленной заболеваемости граждан, увеличение расходов домохозяйств на медицинское обслуживание, увеличение нагрузки на бюджетную систему здравоохранения, сокращение видового разнообразия в акваториях и лесах Ростовской области, снижение качества водных и земельных ресурсов, рост издержек хозяйствующих субъектов в связи с необходимостью дополнительной водоподготовки, снижение доходности хозяйствующих субъектов отрасли растениеводства в связи с экологически обусловленным ухудшением плодородия почв. Совокупность вышеизложенных негативных факторов ухудшает конкурентоспособность Ростовской области на российском и мировом рынках.

4. Особо охраняемая природная территория может являться инструментом, позволяющим минимизировать негативные последствия природопользования крупнейших промышленнохозяйственных агломераций Ростовской области. Развитие сети местных и региональных ООПТ способствует ускоренной регенерации нарушенных экосистем, улучшает комфорт городского пространства.

5. При создании необходимых организационно-экономических предпосылок особо охраняемая природная территория может стать ядром локального туристско-рекреационного кластера, что будет способствовать как повышению качества природной среды, так и позитивному социальноэкономическому эффекту, выражающемуся в формировании новых рынков для субъектов малого и среднего бизнеса региона, создании новых рабочих мест, увеличении налоговых поступлений в консолидированный бюджет.

\section{Библиографический список}

1. Мурзин, А. Д. Нормативно-правовые основы формирования стратегии устойчивого социоэколого-экономического развития урбанизированных территорий / А. Д. Мурзин, Т. Ю. Анопченко // Инженерный вестник Дона. - 2012. - № 4-1 (22). - С. 138-139.

2. Мурзин, А. Д. Комплексная оценка социо-эколого-экономических факторов состояния урбанизированных территорий / А. Д. Мурзин // Региональная экономика: теория и практика. — 2012. — № 8. - C. 44-50.

3. Мурзин, А. Д. Влияние урбанизации на устойчивость комплексного развития территории крупных городов / А. Д. Мурзин // Российский академический журнал. - 2010. - Т. 13, № 3. C. $15-17$.

4. Ревунов, Р. В. Направления модернизации механизма управления природопользованием на региональном уровне / Р. В. Ревунов, С. В. Ревунов // Региональная экономика. Юг России. - 2018. 一 № 3. - С. 156-164.

5. Ревунов, Р. В. Организационно-экономические и нормативно-правовые аспекты повышения эффективности системы управления водопользованием на мезо- и микроэкономическом уровнях / Р. В. Ревунов // Водоочистка. — 2016. — № 4. — С. 41-46. 
6. Ревунов, С. В. Инструменты повышения эффективности природопользования на микро- и мезоэкономическом уровнях / С. В. Ревунов, Д. В. Янченко // Конкурентоспособность в глобальном мире: экономика, наука, технологии. — 2017. — № 3-1 (32). — С. 145-147.

7. Ревунов, С. В. Инструменты стимулирования эффективного использования ресурсного потенциала на региональном уровне / С. В. Ревунов, В. Н. Чумаков, Д. В. Янченко // Конкурентоспособность в глобальном мире: экономика, наука, технологии. - 2016. — № 7-2 (19). - С. 78-82.

8. Конституция Российской Федерации (принята всенародным голосованием 12.12.93) : [Электронный ресурс] / КонсультантПлюс. - Режим доступа: http://www.consultant.ru/document/cons doc LAW_28399/ (дата обращения: 16.01.19).

9. Земельный кодекс Российской Федерации [принят Государственной Думой 28 сентября 2001 года, одобрен Советом Федерации 10 октября 2001 года] : [Электронный ресурс] / КонсультантПлюс. - Режим доступа: http://www.consultant.ru/document/cons doc LAW 33773/ (дата обращения: 16.01.19).

10. Об общих принципах организации местного самоуправления в Российской Федерации : федер. закон : [принят Государственной Думой 16 сентября 2003 года, одобрен Советом Федерации 24 сентября 2003 года] : [Электронный ресурс] / КонсультантПлюс. — Режим доступа: http://www.consultant.ru/document/cons_doc_LAW_44571/ (дата обращения: 26.11.18).

11. О создании особо охраняемой природной территории местного значения на территории муниципального образования «Город Новочеркасск» : постановление администрации г. Новочеркасска № 1459 от 22 сентября 2017 г.: [Электронный ресурс] / Новочеркасск. Официальный сайт города. - Режим доступа: https://novochgrad.ru/acts_doc/view/id/22124/type/doc.html (дата обращения: 16.01.19).

\section{References}

1. Murzin, A.D. Normativno-pravovie osnovi formirovaniya strategii ustoichivogo sotsio-ekologoekonomicheskogo razvitiya urbanizirovannikh territorii. [Normative-legal bases of sustainable social strategy formation, ecological and economic development of urban areas.] Engineers Don Journal, 2012, № 4-1 (22), 138-139 pp. (in Russian).

2. Murzin, A.D. Kompleksnaya otsenka formirovaniya strategii ustoichivogo sotsio-ekologoekonomicheskogo razvitiya urbanizirovannikh territorii. [Comprehensive assessment of social, ecological and economic factors, the condition of urbanized territories.] Regional economy: theory and practice, 2012, № 8, 44-50 pp. (in Russian).

3. Murzin, A.D. Vliyanie urbanizatsii na ustoichivost kompleksnogo razvitiya territorii krupnikh gorodov. [The impact of urbanization on the sustainability of metropolitan area integrated development.] Russian academic journal, 2010, V.13, № 3, 15-17 pp. (in Russian).

4. Revunov, R.V. Napravlenie modernizatsii mekhanizma upravleniya prirodoispolzovaniem na regionalmon urovne. [Directions of modernization at the regional level environmental management mechanism.] Regional economy. The South of Russia, 2018, № 3, 156-164 pp. (in Russian).

5. Revunov, R.V. Organizatsionno-ekonomicheskie I normativno-pravovie sapekti povisheniya effektivnosti sistemi upravleniya vodopolzovaniem na mezo I mikroekonomicheskom urovnyakh. [Organizational-economic and regulatory aspects of increasing the efficiency of water management system for mesa and micro levels.] Water treatment, 2016, № 4, 41-46 pp. (in English).

6. Revunov, S.V. Instrumenti povisheniya effektivnosti prirodopolzovaniya na mikro I mezoekonomicheskom urovnyakh. [Tools which increase the efficiency of natural resources at the micro and mesa levels.] Competitiveness in a globalized world: economics, science, technology, 2017, № 3-1 (32), 145-147 pp. (in Russian).

7. Revunov, S.V. Instrumenti stimulirovaniya effektivnogo ispolzovaniya resursnogo potentsiala na regionalnom urovne. [Instruments promoting the efficient use of the resource potential at the regional level.] 
Competitiveness in a globalized world: economics, science and technology, 2016, № 7-2 (19), 78-82 pp. (in Russian).

8. Konstitutsiya Rossiiskoi Federatsii (prinyata vsenarodnim golosovaniem 12.12.93). [The Constitution of the Russian Federation (adopted by popular vote 12.12.93] (in Russian).

9. Zemelnii kodeks Rossiiskoi Federatsii (prinyata Gosudarstvennoi Dumoi 28 sentaybrya 2001 goda. [ The Land Code of the Russian Federation [adopted by the State Duma on September 28, 2001, the Federation Council approved October 10, 2001] (in Russian).

10. Ob obschikh printsipakh organizatsii mestnogo samoupravleniya v Rossiiskoi Federatsii. [On general principles of local government organization in the Russian Federation: the fader. Law: [adopted by the State Duma on September 16, 2003, the Federation Council approved September 24, 2003] (in Russian).

11. O sozdanii osobo okhranyaemoi prirodnoi territorii mestnogo znacheniya na territorrii mestnogo znacheniya na territorii munitsipalnogo obrazovaniya "Gorod Novocherkassk". [ On the establishment of specially protected natural territories of local importance in the territory of the municipality "City of Novocherkassk": decree of the administration Novocherkassk No 1459 of September 22, 2017] (in Russian).

Поступила в редакцию 20.12 .2018

Сдана в редакцию 20.12.2018

Запланирована в номер 22.01.2019
Received 20.12.2018

Submitted 20.12.2018

Scheduled in the issue 22.01.2019

\section{Об авторе:}

\section{Мурзин Антон Дмитриевич,}

доцент кафедры «Управление развитием пространственно-экономических систем» Южного федерального университета (РФ, 344006, г. Ростов-на-Дону, ул. Большая Садовая, 105/42), кандидат экономических наук, доцент admurzin@sfedu.ru

\section{Ревунов Роман Вадимович,}

доцент кафедры «Экономика и прикладная математика» Южного федерального университета (РФ, 344006, г. Ростов-на-Дону, ул. Большая Садовая, 105/42), кандидат экономических наук, доцент
Author:

\section{Murzin, Anton D.,}

Associate Professor, department of "Management of space-economic systems", Southern Federal University (105/42, str. Bolshaya Sadovaya, Rostov-on-Don, 344006, RF), PhD, Associate Professor admurzin@sfedu.ru

\section{Revunov, Roman V.,}

Associate Professor, the department of "Economics and Applied Mathematics" Southern Federal University (105/42, str. Bolshaya Sadovaya, Rostovon-Don, 344006, RF), PhD, Associate Professor 